Pacific Northwest

National Laboratory

Operated by Battelle for the

U.S. Department of Energy

\section{Final Report Providing the Design for Low-Cost Wireless Current Transducer and Electric Power Sensor Prototype}

\author{
M. Kintner-Meyer \\ B. Burghard \\ L. D. Reid
}

December 2004

\footnotetext{
Prepared for the U.S. Department of Energy
} under Contract DE-AC05-76RL01830 


\section{DISCLAIMER}

This report was prepared as an account of work sponsored by an agency of the United States Government. Neither the United States Government nor any agency thereof, nor Battelle Memorial Institute, nor any of their employees, makes any warranty, express or implied, or assumes any legal liability or responsibility for the accuracy, completeness, or usefulness of any information, apparatus, product, or process disclosed, or represents that its use would not infringe privately owned rights. Reference herein to any specific commercial product, process, or service by trade name, trademark, manufacturer, or otherwise does not necessarily constitute or imply its endorsement, recommendation, or favoring by the United States Government or any agency thereof, or Battelle Memorial Institute. The views and opinions of authors expressed herein do not necessarily state or reflect those of the United States Government or any agency thereof.

\section{PACIFIC NORTHWEST NATIONAL LABORATORY operated by \\ BATTELLE for the UNITED STATES DEPARTMENT OF ENERGY under Contract DE-AC05-76RL01830}

Printed in the United States of America

$$
\begin{aligned}
& \text { Available to DOE and DOE contractors from the } \\
& \text { Office of Scientific and Technical Information, } \\
& \text { P.O. Box 62, Oak Ridge, TN } 37831-0062 \text {; } \\
& \text { ph: (865) } 576-8401 \\
& \text { fax: (865) } 576-5728 \\
& \text { email: reports@adonis.osti.gov }
\end{aligned}
$$

\footnotetext{
Available to the public from the National Technical Information Service, U.S. Department of Commerce, 5285 Port Royal Rd., Springfield, VA 22161 ph: (800) 553-6847 fax: (703) 605-6900 email: orders@ntis.fedworld.gov online ordering: http://www.ntis.gov/ordering.htm 


\title{
Final Report Providing the Design for Low-Cost Wireless Current Transducer and Electric Power Sensor Prototype
}

\author{
M. Kintner-Meyer \\ B. Burghard \\ L. D. Reid
}

December 2004

\author{
Prepared for \\ the U.S. Department of Energy \\ Office of Energy Efficiency and \\ Renewable Energy \\ under Contract DE-AC05-76RL01830
}

Pacific Northwest National Laboratory

Richland, Washington 99352 


\section{Summary}

This report describes the design and development of a wireless current transducer and electric power sensor prototype. The prototype was developed for demonstration purposes. The report includes annotated schematics of the power sensor circuitry and the printed circuit board. ${ }^{1}$ The application program used to illustrate the functionality of the wireless sensors also is described in this document. The software was written to graphically display and archive the user-selectable measured electric properties, such as electric current, voltage, and real power, in near real-time as they are received from one or more wireless sensors.

This prototype demonstrates the concept of wireless end-use power metering. By testing it in the building environment, the limitations that need to be overcome in a practical device for field deployment can be identified. It can also be used to demonstrate the concept to potential users of wireless end-use power meters as an aid in eliciting their input for the design of practical, fielddeployable, wireless devices.

\footnotetext{
${ }^{1}$ Reference to specific equipment models and trade names is for accurate documentation of the research only and does not constitute endorsement by PNNL.
} 


\section{Contents}

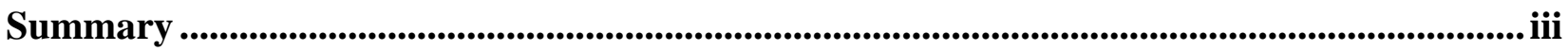

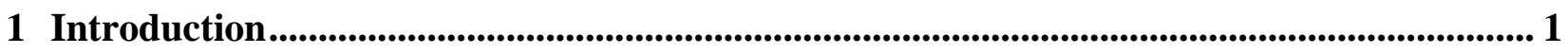

2 Overview of the Sensor Prototype .............................................................................................. 2

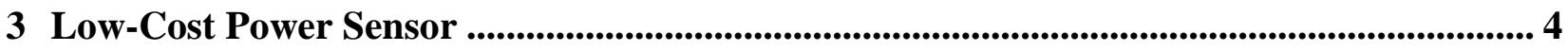

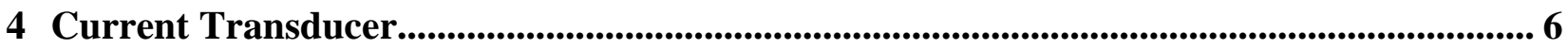

5 Description of Integrated Wireless Current Transducer and Power Sensor Prototype ..... 7

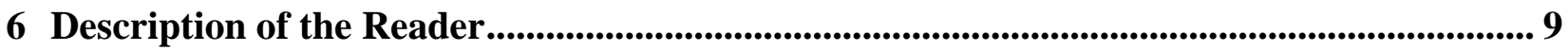

7 Description of the Wireless Sensor Application Program...................................................... 10

7.1 Introduction .......................................................................Error! Bookmark not defined.

7.2 Wireless Sensor Application Program ........................................................................ 10

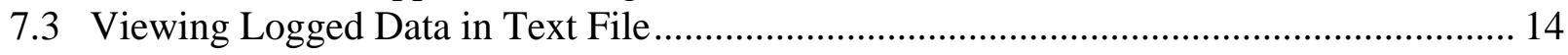

7.4 Cirrus Chip Read/Write Register Utility Panel ........................................................... 16

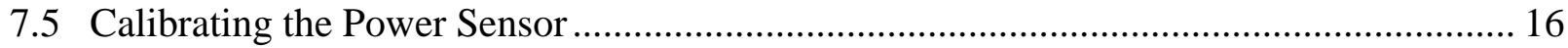

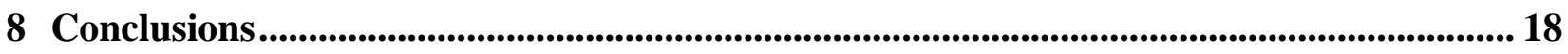

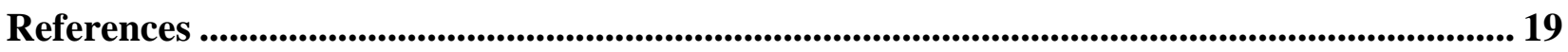




\section{Figures}

Figure 2-1. Block Diagram of Major Components of the Wireless Sensor Prototype..................2

Figure 2-2. Wireless Sensors, Reader and Computer.......................................................... 3

Figure 3-1. Schematic of Current Transducer and Power Meter .............................................. 4

Figure 3-2. Layout of Printed Circuit Board of Current Transducer and Power Meter ................. 5

Figure 5-1. View of the Integrated Sensor and RF Transceiver with its Case Open. ...................8

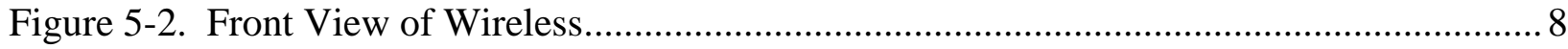

Figure 5-3. Side View of Wireless Sensor ................................................................. 8

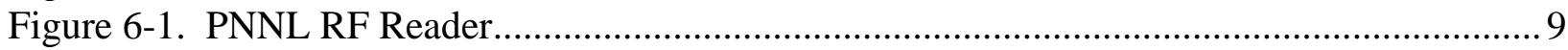

Figure 7-1. Startup Procedure ...................................................................................... 10

Figure 7-2. Initial WattMeter screen. ........................................................................... 11

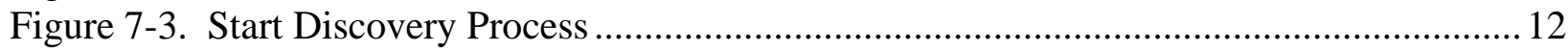

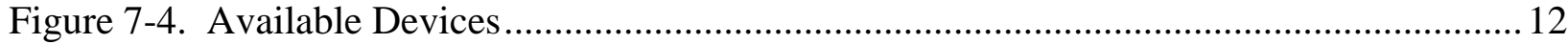

Figure 7-5. Real-time chart of selected parameter ........................................................... 14

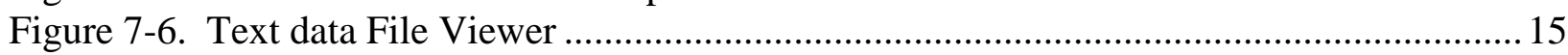

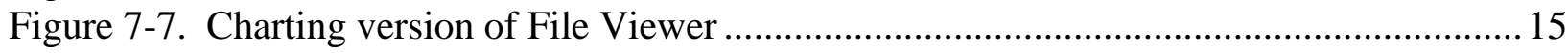

Figure 7-8. Read/Write Cirrus Register Utility ................................................................... 16 


\section{Acronyms}

$\mathrm{A} / \mathrm{C}$

CT

FCC

IC

IRMS

$\mathrm{RF}$

VRMS alternating current

current transducer

Federal Communications Commission

integrated circuit

root mean square of the $\mathrm{A} / \mathrm{C}$ current I

radio frequency

root mean square of the $\mathrm{A} / \mathrm{C}$ voltage $\mathrm{V}$ 


\section{Introduction}

The need to better understand and manage electricity use and the need for a low-cost means by which to collect electricity end-use data for the purpose of automated diagnostics motivated the development of a wireless current transducer and power sensor in this task. The convergence of technological advancements in electronics and the emergence of markets that reward electric power consumers when they limit their peak demand during high price periods or during grid emergencies make this development possible and timely. Furthermore, the resulting technology will enable advanced diagnostics that represent a critical cornerstone to achieving and maintaining high energy efficiency in HVAC equipment and other energy using systems in buildings at reasonable cost. The overall goal of the first phase of this project is to demonstrate at the proof-ofconcept level a wireless device that incorporates the technical capability to measure the electric power use of an end-use device and communicate the measured data wirelessly to a central station for display and data archiving.

The use of wireless radio frequency technology is an essential component of the prototype development effort. By communicating data wirelessly, expensive wiring cost can be avoided. By integrating an unlicensed radio frequency transmitter with a low-cost sensor, it is hoped that this prototype will generate some interest by the sensor and controls industry to initiate new product development efforts that will lead to lower cost control and sensor products for HVAC and other buildings applications.

Wireless sensors are enablers of advanced diagnostics and controls of commercial buildings. The U.S Department of Energy in its Commercial Buildings Roadmap identifies wireless sensors and controls as cornerstones and key contributors for high performance building operations [DOE 2000]. With low-cost wireless sensor and control systems, not only will the cost of control system installation be significantly reduced, but it will become economical to use more sensors, thereby establishing highly energy efficient building operations and demand responsiveness that will enhance our electric grid reliability.

The result of this project is a wireless sensor prototype that illustrates the major components of a low-cost sensor and communication design. By no means is the sensor prototype optimized for performance or cost. However, the prototype development provides a first step toward a low-cost wireless power and current end-use metering device that, by careful design and use of the latest electronics technology, over time can be sold for a fraction of today's commercially available end-use metering technology. 


\section{Overview of the Sensor Prototype}

The wireless sensor prototype consists of one reader device and one or more sensor devices. The reader is connected to a desktop or laptop computer via an RS-232 serial port. The reader polls each individual sensor to collect the most current sensor data. The received data can then be displayed in near real-time and archived in a text file. The sensor is capable of measuring up to six individual electric currents using commercially available current transducers whose outputs are connected to the sensor. A typical application for the use of such a sensor would be to diagnose the operation of either six single-phase loads or two three-phase pieces of equipment (e.g., pump and compressor motors) or a combination of both. Alternatively, a single-phase 120-Volt alternating current (A/C) load can be plugged into the sensor. The sensor will then provide the electric power to the load as well as measure the electric power consumed by the load. The typical application for this use of the wireless sensor is end-use metering.

Figure 2-1 shows a block diagram of the major components of the reader and sensor devices. Although loads are shown connected to both the receptacle and the current transducers in this figure, only one or the other input can be used at a time on this device, not both. Figure 2-2 provides a picture of three wireless sensors and the reader connected to a laptop computer.

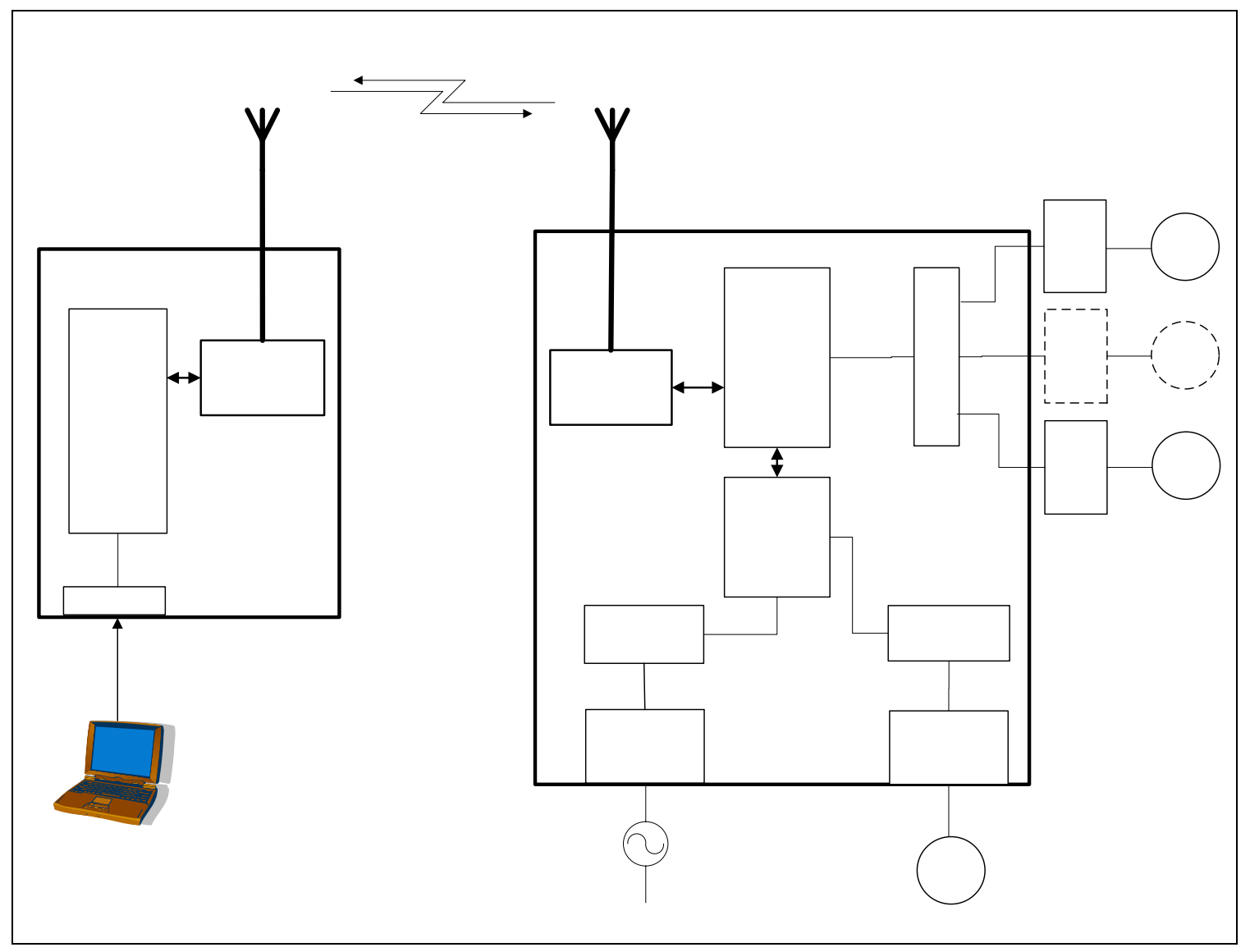

Figure 2-1. Block Diagram of Major Components of the Wireless Sensor Prototype 


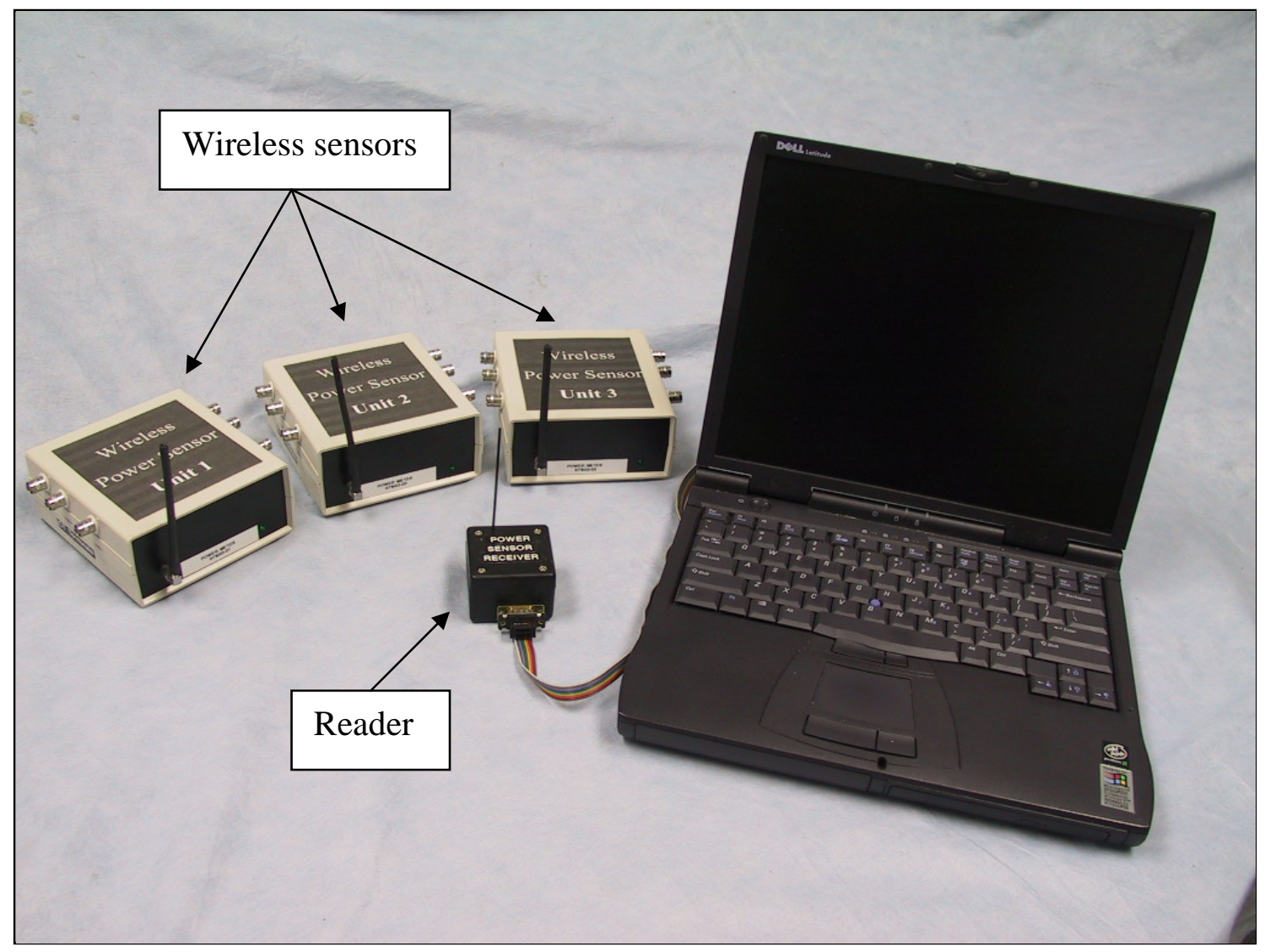

Figure 2-2. Wireless Sensors, Reader and Computer

The sections that follow discuss in further detail the design of the single-phase 120-Volt $\mathrm{A} / \mathrm{C}$ power meter, the electrical current transducers, and the integration of the sensor with a Pacific Northwest National Laboratory (PNNL) transceiver. 


\section{Low-Cost Power Sensor}

The power sensor design is based around a single-phase power integrated circuit (CS5460A Power Meter IC) manufactured by Cirrus Logic ${ }^{2}$. This IC provides simultaneous voltage and current measurements and electric energy metering at user definable intervals [Cirrus 2002].

The CS5460A is a highly integrated analog-to-digital (A/D) converter that combines two A/D converters and high-speed power calculation functions on a single chip. It is designed to accurately measure and calculate energy, instantaneous power, root mean square of the A/C current (IRMS) and the voltage (VRMS) for single-phase, two- or three-wire power metering applications. The CS5460A features a serial interface for communication with a microcontroller.

The price for the Cirrus IC is $\$ 4.00$ when purchased in small quantities. The manufacturer target price at high volume fabrication is $\$ 1.50$. At the current time, however, the manufacturer does not provide further discounts for high volume purchases. The cost of additional electronic components for the end-use power meter, including the printed circuit board, was estimated to be approximately $\$ 20$ for one power sensor.

The schematic for the power sensor is shown in Figure 3-1, and the printed circuit board is shown in Figure 3-2.

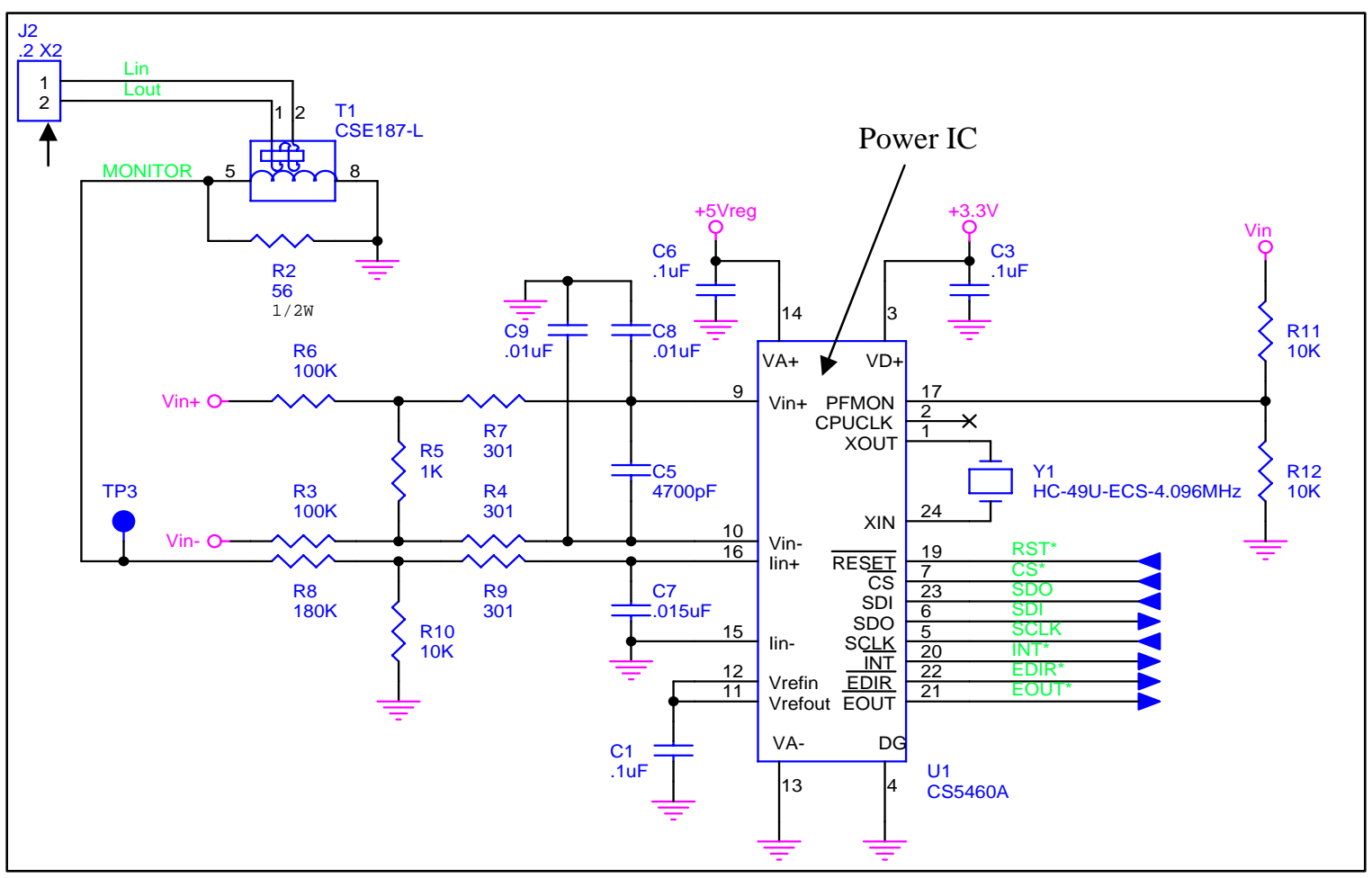

Figure 3-1. Schematic of Current Transducer and Power Meter

\footnotetext{
${ }^{2}$ More information can be obtained at http://www.cirrus.com
} 


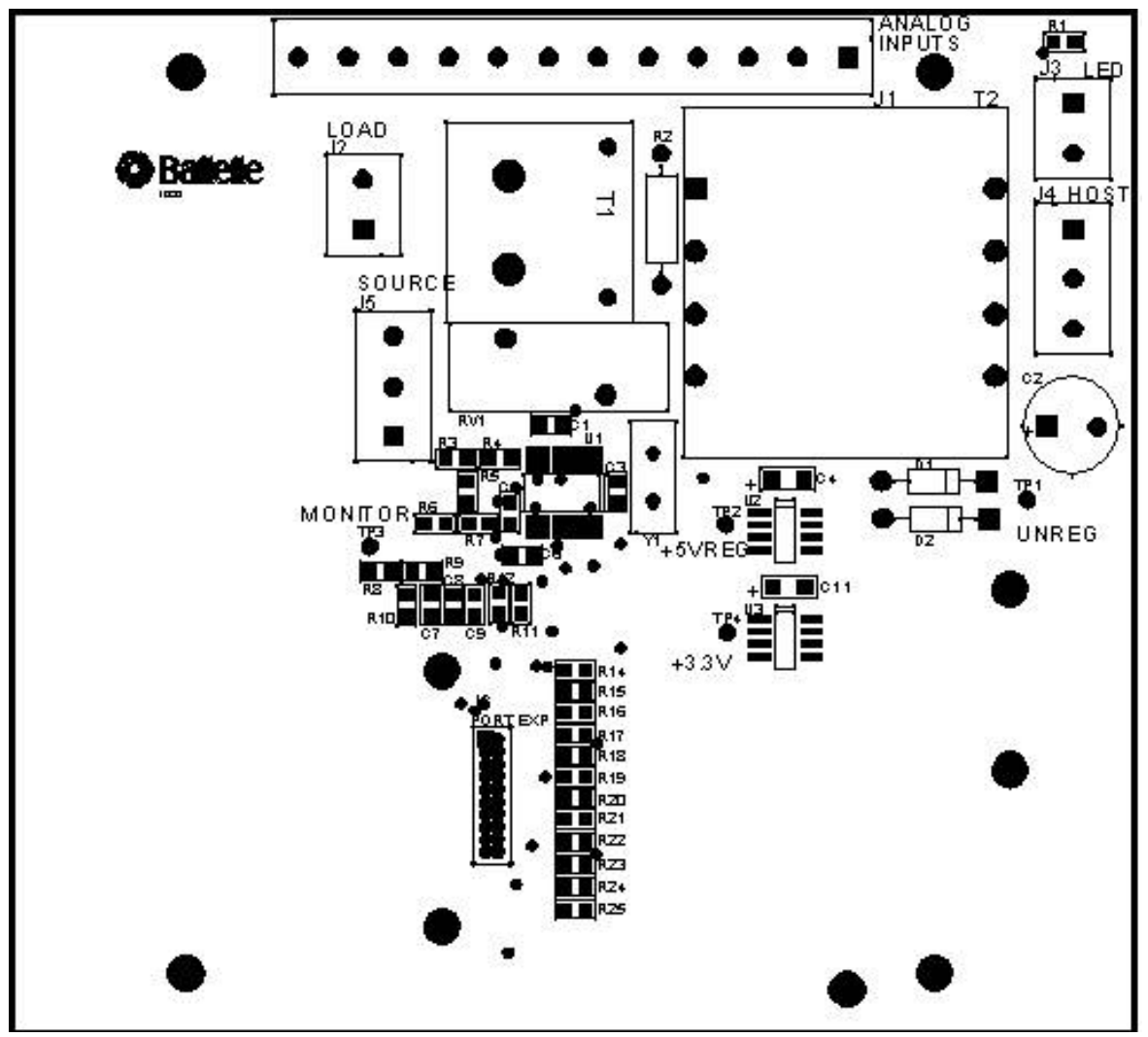

Figure 3-2. Layout of Printed Circuit Board of Current Transducer and Power Meter 


\section{Current Transducer}

Current measurements are performed using a commercially available current transducer, which consists of an open-core coil that is placed around the conductor, whose current is to be measured. We use open-core current transducers with selectable amperage ranges of 30, 60, and 120 Amperes. [Veris 2003] The electrical current in the conductor induces a voltage in the coil, which is proportional to the current in the conductor.

As described further below, the voltage output from the current transducer is fed directly into the wireless transceiver for transmission to the host PC for viewing and data logging. 


\section{Description of Integrated Wireless Current Transducer and Power Sensor Prototype}

For wireless communication of the measured signals, we selected a radio frequency (RF) transceiver developed by PNNL. The PNNL RF transceiver can be fabricated at a cost of approximately $\$ 50$ - $\$ 70$ for a small production series of less than 20 units.

The PNNL transceiver transmits at a single frequency of $916 \mathrm{MHz}$. The technology has achieved a range of 50 to $100 \mathrm{ft}$ in testing with line-of-sight communication at an output power of $0.25 \mathrm{~mW}$. The data rate is 4800 bits per second. The PNNL transceiver is compliant with Federal Communications Commission (FCC) Part 15, which regulates the unlicensed industrial, scientific, and medical radio frequency bands [FCC 2004]. More detailed information on the PNNL transceiver can be found in [Lechelt et al. 2002)].

The PNNL RF transceiver platform consists of a reader device and a sensor-transceiver device. The reader is connected to a computer via an RS232 interface. The reader first broadcasts a signal to find out how many sensor-transceiver devices are within range. The sensor-transceivers respond to the reader's broadcast by sending back their unique ID numbers. The reader then establishes a call-up sequence that sequentially interrogates each the sensor-transceiver devices that is registered during the first initialization broadcast. Each sensor-transceiver is then interrogated individually for its most recent data values.

Figure 5-1 provides a view into the integrated sensor-transceiver device, and Figure 5-2 and Figure 5-3 show the fabricated sensor device from two different perspectives. 


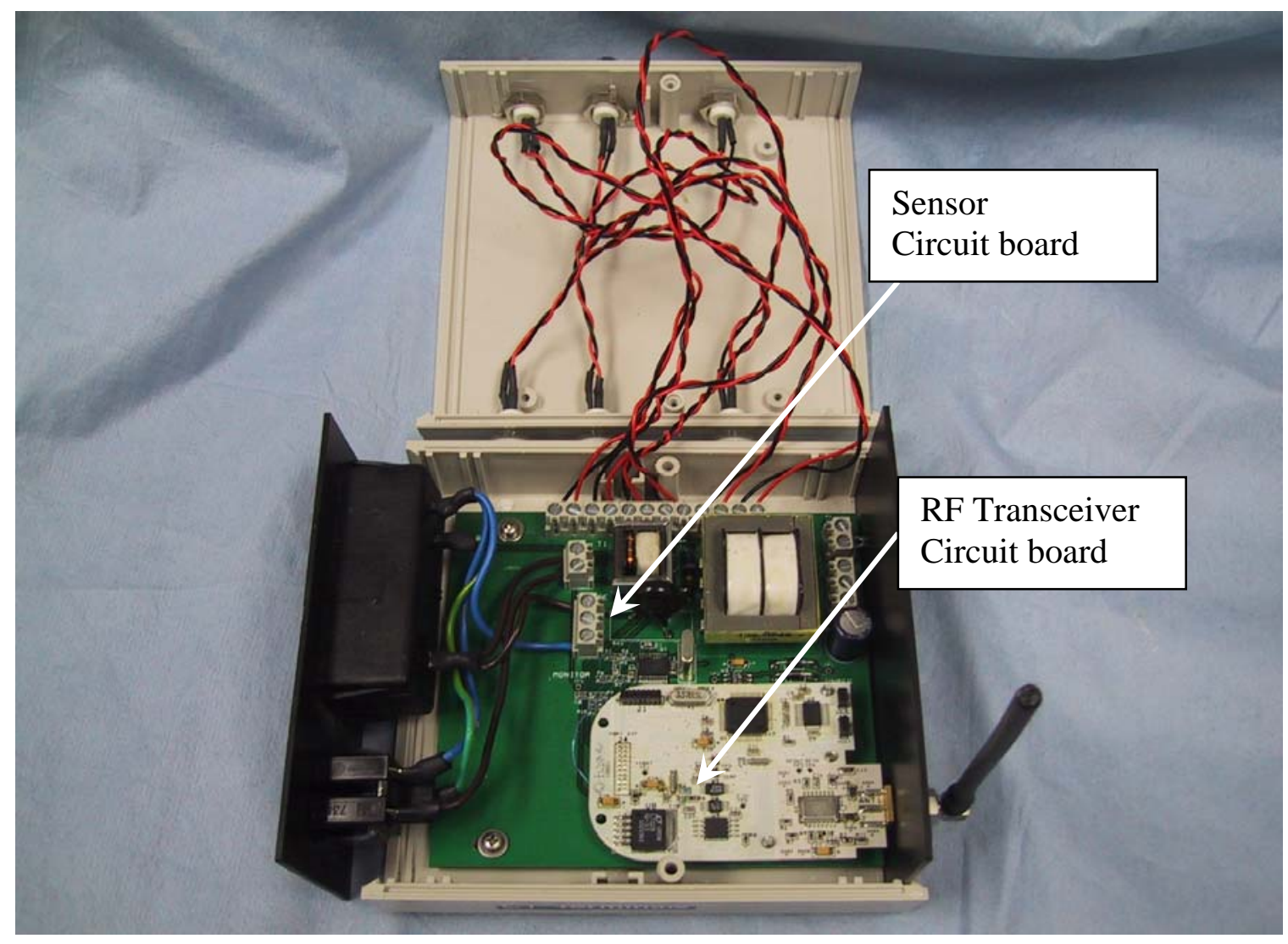

Figure 5-1. View of the Integrated Sensor and RF Transceiver with its Case Open.

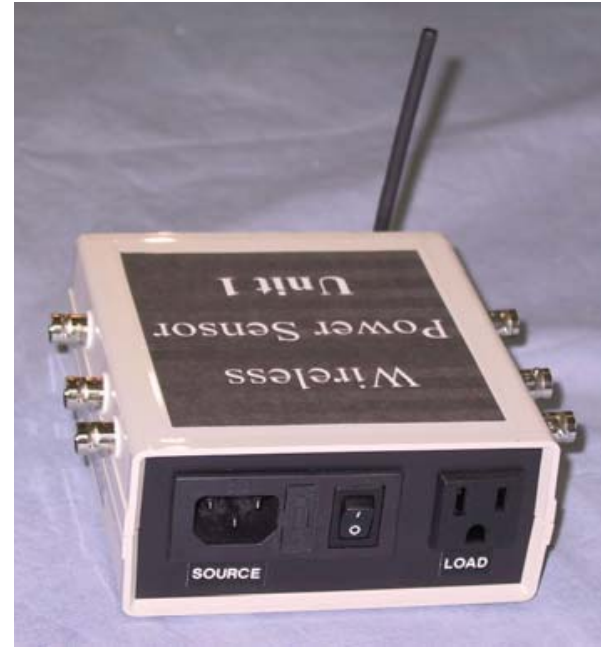

Figure 5-2. Front View of Wireless Sensor

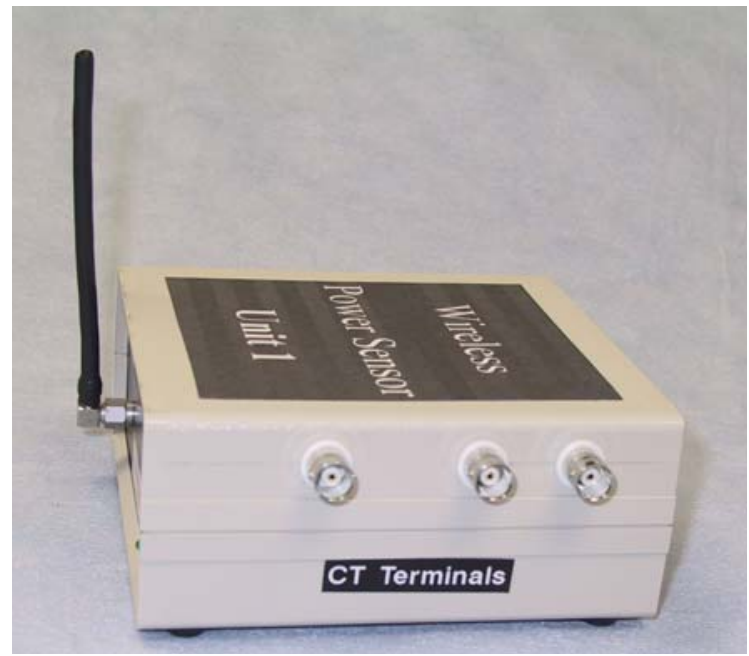

Figure 5-3. Side View of Wireless Sensor 


\section{Description of the Reader}

The reader is based on the identical transceiver technology as described for the sensor. The printed circuit board design is optimized for small size. More information can be found in [Lechelt, et al. 2002]. Figure 6-1 provides a picture of the reader device with its serial cable for connection to a computer.

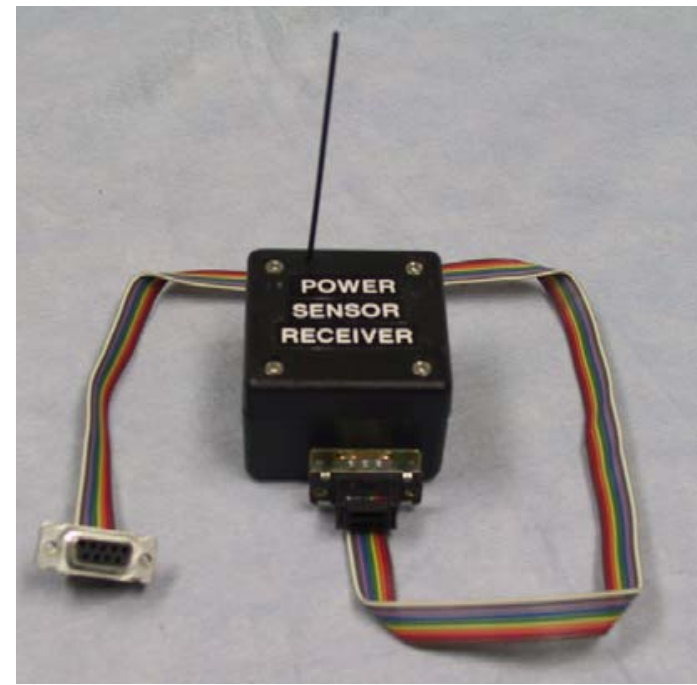

Figure 6-1. PNNL RF Reader 


\section{Description of the Wireless Sensor Application Program}

This section describes an application program written in Visual Basic 6.0 [Microsoft 2001] that controls the wireless communication between a computer and the wireless sensor devices. The program provides the following features:

- Identification of wireless sensors within reception range

- Selection of monitoring using the integrated power sensor or external current transducers

- Selection of specific data monitoring and archiving

- Calibration of sensors.

Each feature of the application program is described in more detail below.

\subsection{Wireless Sensor Application Program}

The sensor application program is titled "WattMeter." It is written in Microsoft Visual Basic 6.0 and is compatible with all Microsoft 32-bit operating systems (Windows 98, ME, NT, 2000, and XP).

To initialize the communication to all available wireless sensors, WattMeter causes the Reader module to broadcast a signal eliciting return signals from all receiving wireless sensors. Following this discovery process, the user is presented with a list of available sensor units. The user selects the sensor unit and the electrical property to be monitored. The sequence of steps is illustrated in Figure 7-1 and described in the following section.

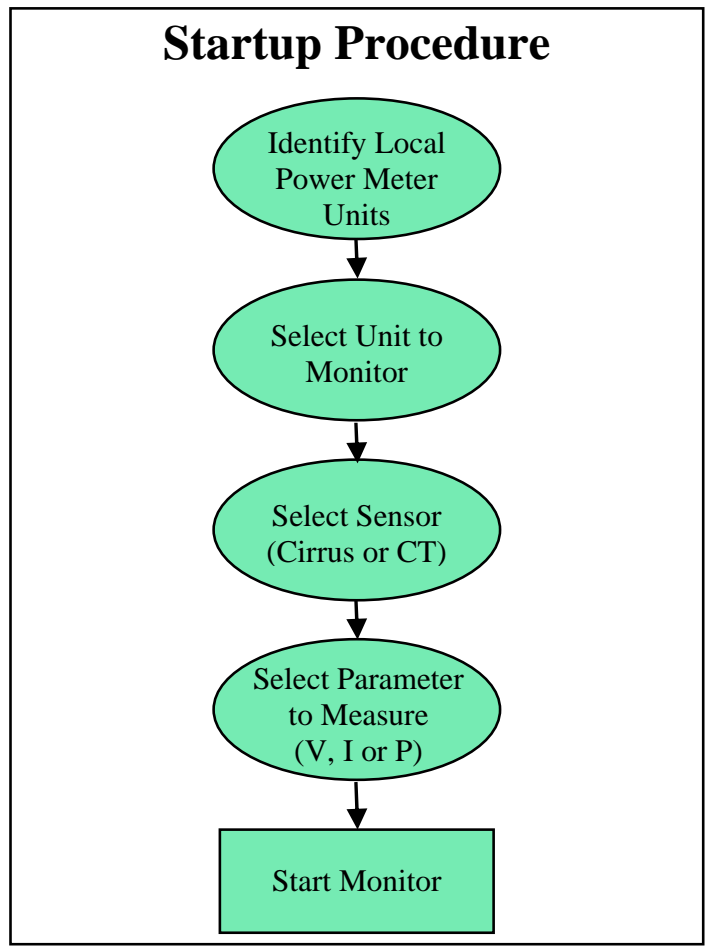

Figure 7-1. Startup Procedure 


\section{Step 1: Initiate the Discovery Process of Wireless Sensors within Range}

After invoking the "WattMeter" program, the initial screen, shown in Figure 7-2, can be seen. Use the mouse to select "Start" from the "Main" menu (or Ctrl S from the keyboard).

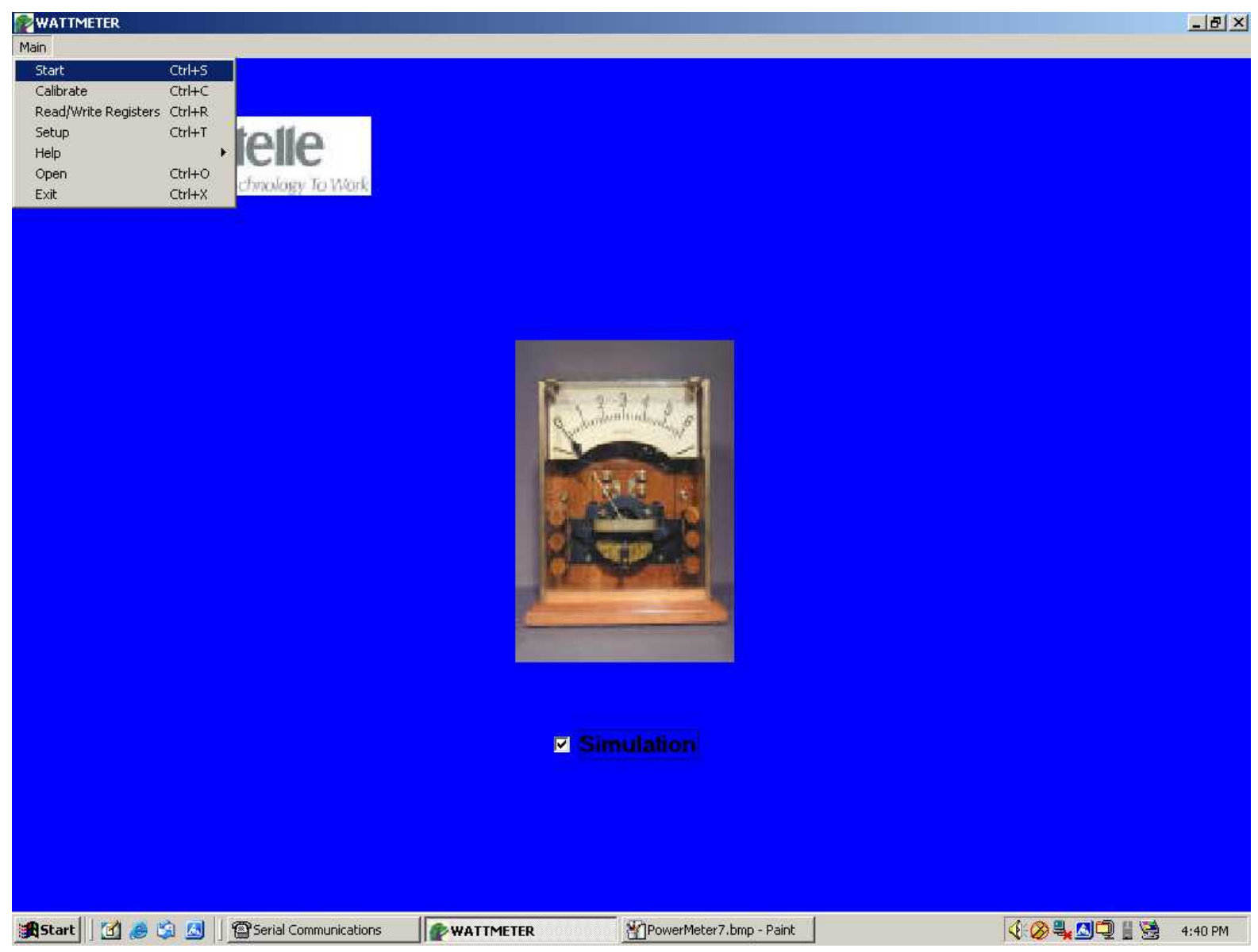

Figure 7-2. Initial WattMeter screen.

The user will then see the screen shown in Figure 7-3. Click on the START button on the "Display Active Tag List” panel to initiate the discovery process. This is a polling procedure that requests each sensor to report its unique identifier. The wide status box at the bottom of the screen (just above the EXIT button) displays the status information during the polling process.

After discovery is completed, the "Display Active Tag List" panel is populated with information extracted from the units within range of the reader (see Figure 7-4). 


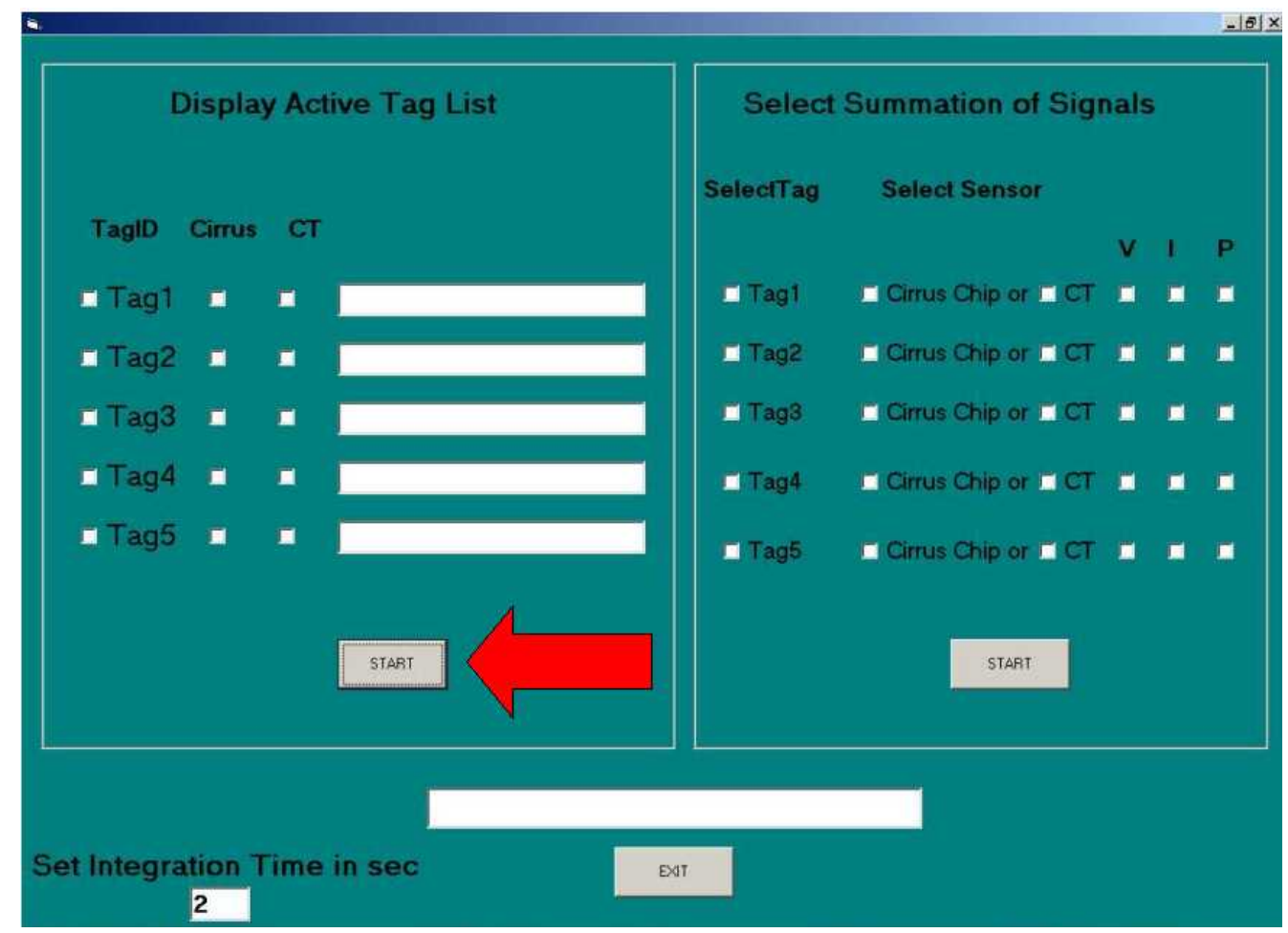

Figure 7-3. Start Discovery Process

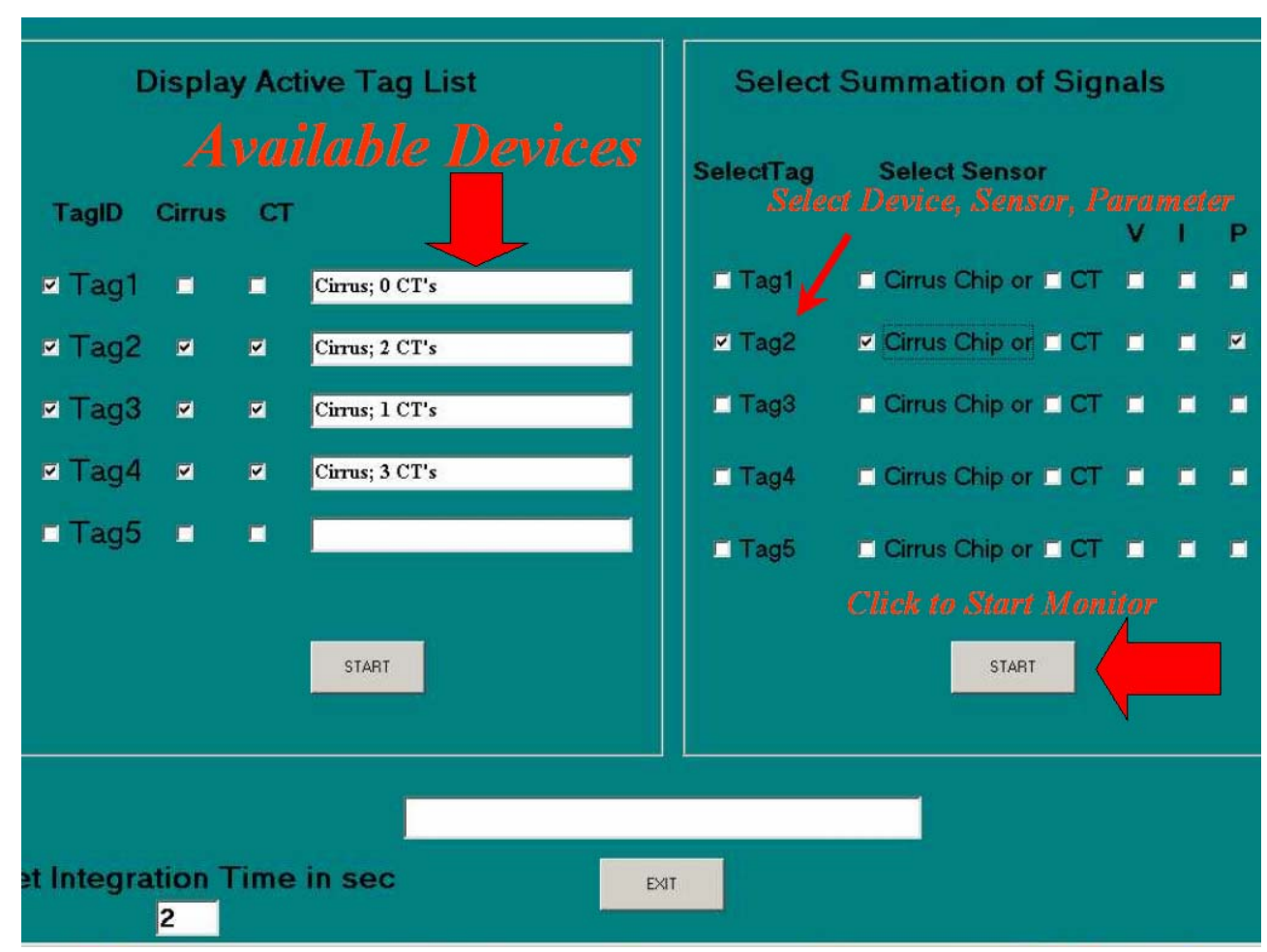

Figure 7-4. Available Devices 


\section{Step 2: Select Device, Sensor, and Electric Property}

Select the sensor device (Tag 1 through 5), sensor (Cirrus Chip or Current Transducer $(\mathrm{CT})$ ), and one of three electric properties (voltage V, current I, real power P) to monitor in the "Select Summation of Signal” panel (see Figure 7-4).

If the selected unit contains a Cirrus Chip, the user may check the Cirrus Chip check box and either V (voltage), I (current), or P (power) to monitor. If the unit has a CT connected to it, then the user may select CT and I (current) to monitor.

\section{Step 3: Monitoring the Selected Property}

Once the sensor and electrical property have been selected, click on the START button in the "Select Summation of Signals" to begin monitoring. The monitor screen will display automatically.

The monitor screen displays a time series of the selected sensor parameter's data in near real-time as sample points are collected from the selected sensor unit. Data displayed in the chart are also saved to a text file. The file name has the format MM-DD-YYYY.dat, where MM is the month, DD is the day, and YYYY is the year. Each row in the file contains time-stamped readings of the selected sensor properties.

A time series of the selected parameters is displayed in near real-time as data points are acquired from the selected device. The update interval is two seconds and is displayed in the bottom left display labeled "Integration time in sec" (see Figure 7-4).

Figure 7-5 shows the graphical representation of the time series recorded from a power sensor device to which two lamps were connected. The first section of the time series shows the power consumption of the 60 Watt light bulb followed by a section during which a 100 Watt light bulb was added. The third section of the time series shows a 100 Watt load, after the first light bulb (60 Watt) was turned off.

Command buttons at the right of the chart allow the following functions to be selected:

- Save: Save a snapshot of the data display

- Clear: Clear the data array and continue acquiring new data

- Setup: Adjust the chart parameters

- Pause: Disable update of the chart display (new data points continue to be recorded in the background)

- Print: Send the chart to a printer

- Exit: Return to the previous screen 


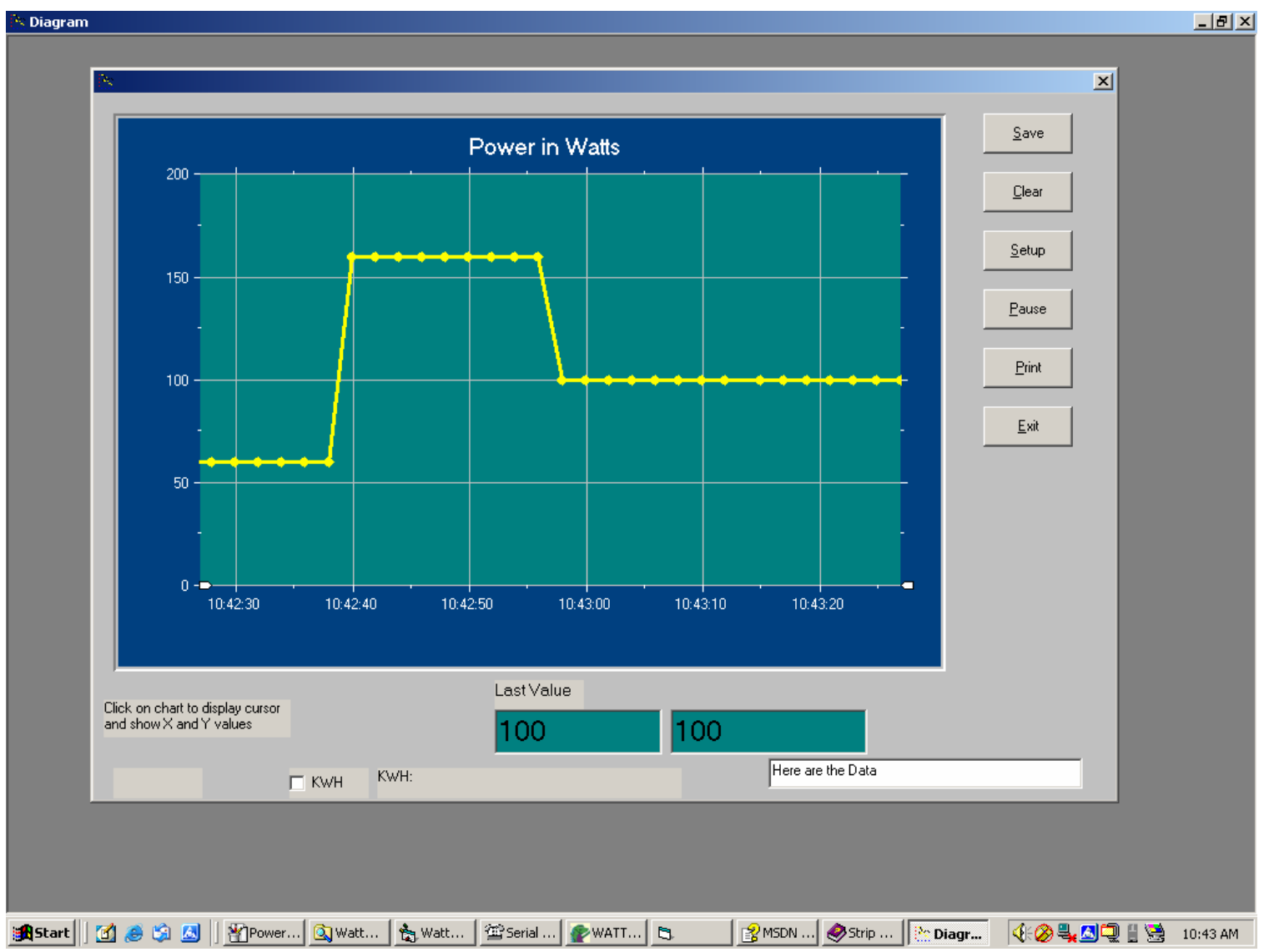

Figure 7-5. Real-time chart of selected parameter

\subsection{Viewing Logged Data in Text File}

All received data that are graphically displayed in the chart are also written to a text file, each with a date and time stamp. The text file may be opened from the main application screen's menu for graphical display of archived data.

To do that, select "Main," then "Open" with the mouse (or Ctrl O from the keyboard to open the File Viewer). From this screen, select "File," then "Open Text” to open a file dialog to select a data file to view as text (see Figure 7-6). Alternately, select "File", "Open Chart" to open up a file dialog to select a data file to view as a chart (see Figure 7-7). From the chart version of the file viewer, the user may select which of the sensor parameters to view with the radio buttons at the bottom of the screen. 


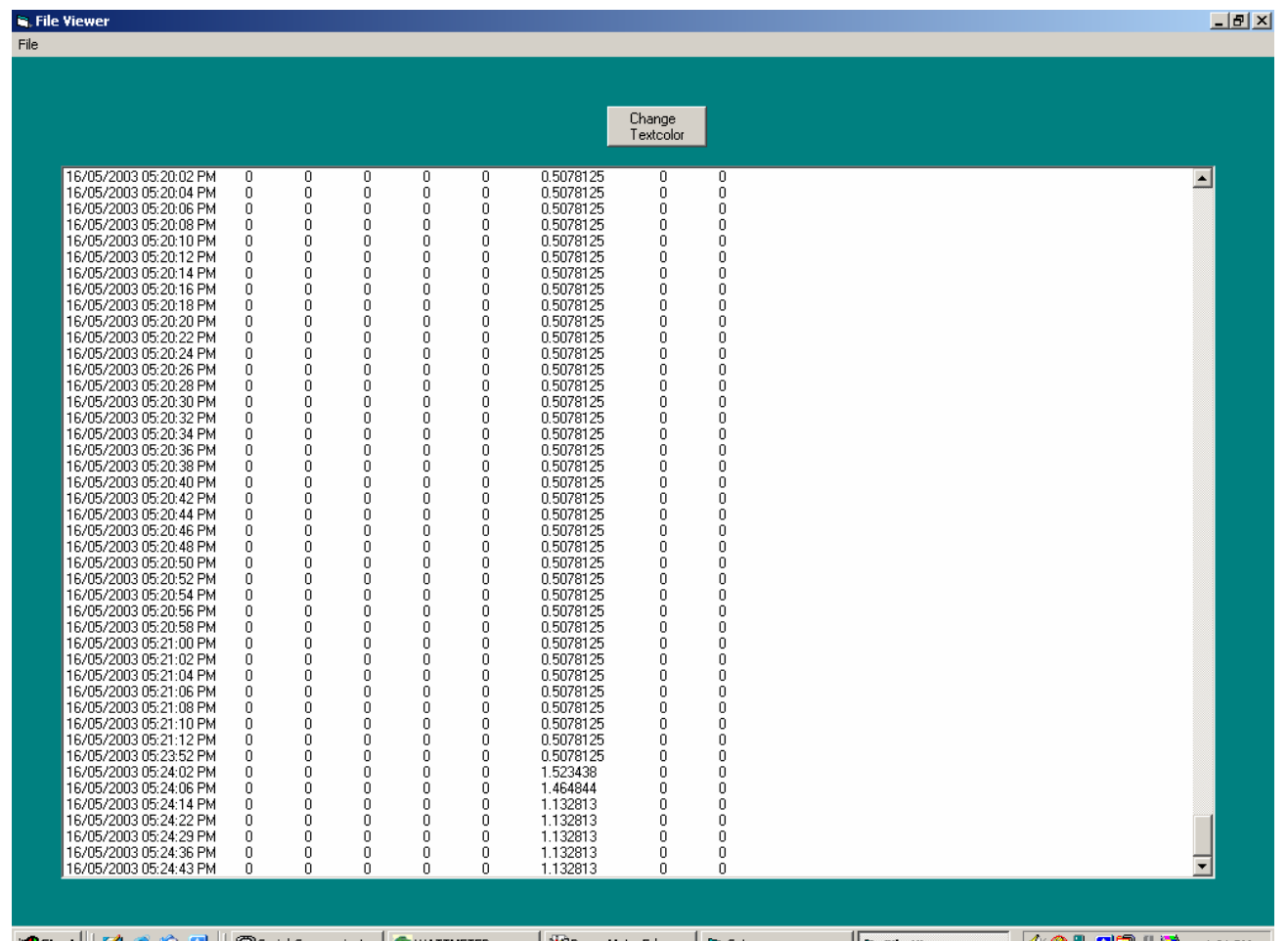

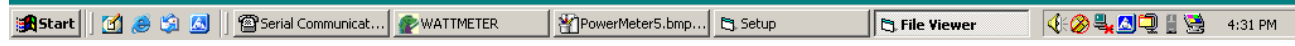

Figure 7-6. Text data File Viewer

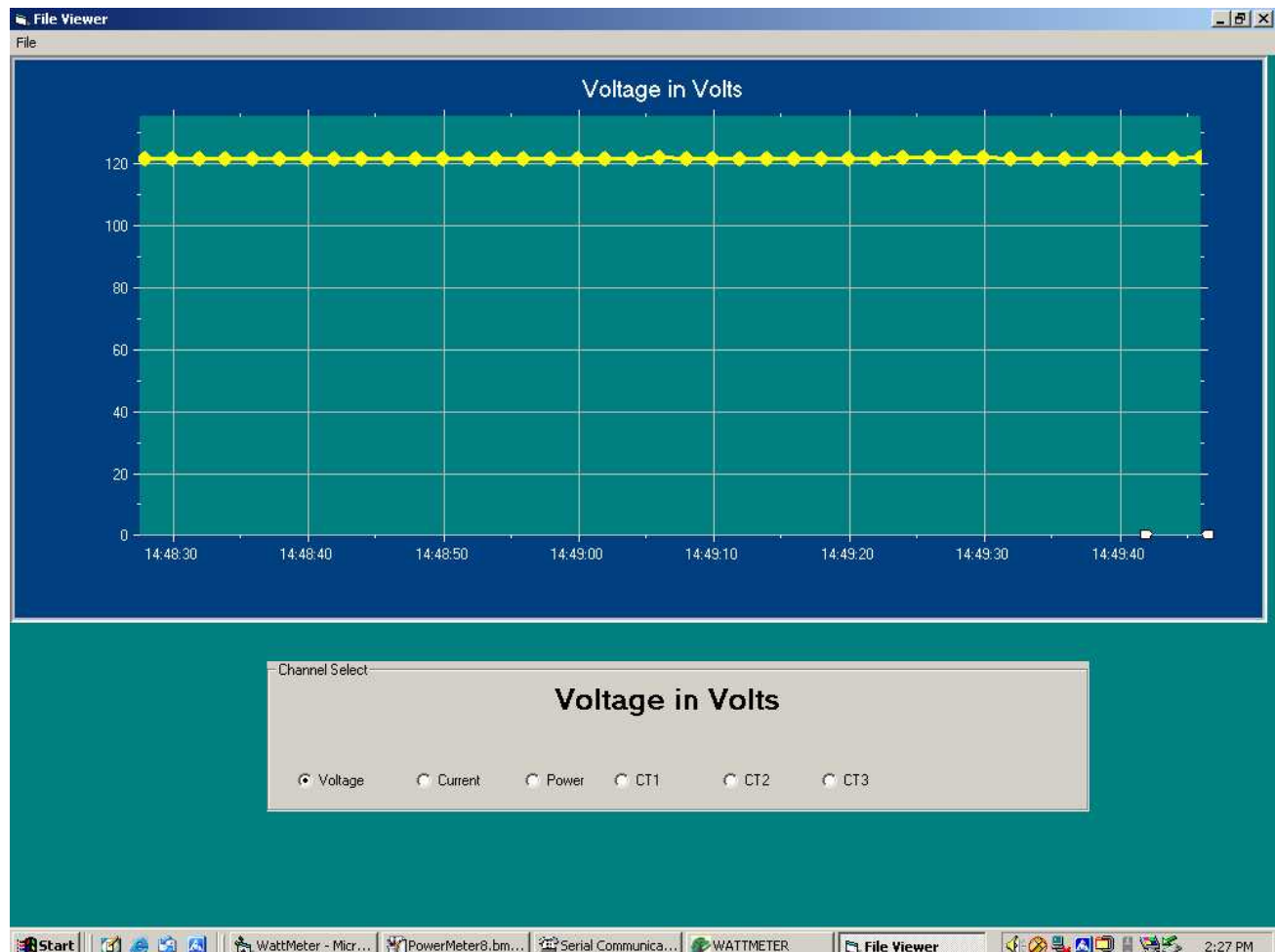

Figure 7-7. Charting version of File Viewer 


\subsection{Cirrus Chip Read/Write Register Utility Panel}

A utility panel is available from the main application screen's menu (see Figure 7-2) to directly read from and write to the chip's registers (see Figure 7-8). This is useful for calibration and troubleshooting. Select "Read/Write Registers" from the "Main" menu with the mouse (or Ctrl R from the keyboard) to bring up this utility panel. Only expert users should use this feature because writing to the chip registers can change the calibration of the device.

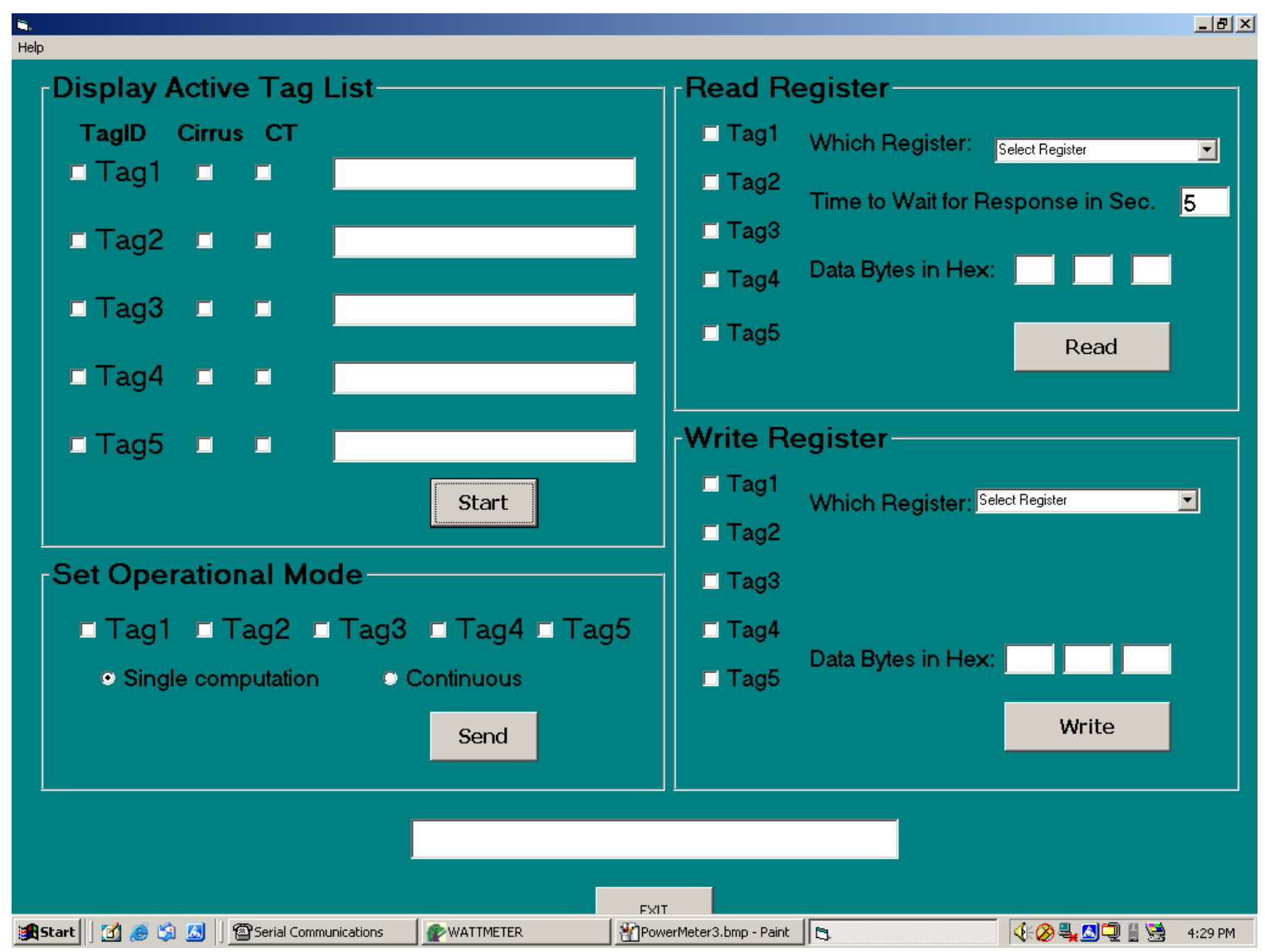

Figure 7-8. Read/Write Cirrus Register Utility

\subsection{Calibrating the Power Sensor}

The measurements taken from the power IC are dependent on the calibration register values (offset and gain) and acquisition parameters on the Cirrus chip. Refer to Application Note for the Cirrus CBD5460A [Cirrus 2002] for a more complete description of the calibration procedure.

The measured values read from the Cirrus CS5460A's output registers must be converted to engineering units. The relationship between register values and engineering values is linear and thus can be represented by a linear equation. Some output registers are 
presented as signed values in the range -1 to 1 for instantaneous values of the alternating current properties (e.g., current (I) and voltage (V)). Other registers are presented using unsigned binary form in the range 0 to 1 (for example: $I_{R M S}, V_{R M S}$ ). The range that these values represent is a function of the calibration factors stored in the registers. The conversion formulas may be established directly over a fixed range by presenting various loads to the power meter and reading the raw register values directly. For example, to determine the conversion or calibration formula for converting readings from the instantaneous power register to Watts over the input range of 0 to 100 Watts, we may read and record the register value with no load and a 100-Watt load.

These two register values associated with 0 and 100 Watt loads are then used to determine the slope and intercept in the linear relationship:

Power $($ in Watts) $=$ slope $\mathrm{x}$ register value + intercept.

This relation is coded into the application program. Engineering conversions are calculated automatically, and displayed on the monitor. 


\section{Conclusions}

A prototype of a wireless current transducer and power sensor was developed for demonstration purposes. Software was written to graphically display and archive the userselectable measured electric properties such as electric current, voltage, and real power in near real-time, which are received from one or more wireless sensors.

This prototype demonstrates the concept of wireless end-use power metering. By testing it in the building environment, limitations that need to be overcome in a practical device for field deployment can be identified. It can also be used to demonstrate the concept to potential users of wireless end-use power meters as an aid in eliciting their input to the design of practical, field-deployable, wireless devices. 


\section{References}

Cirrus. 2002. CBD5460A Evaluation Board and Software. Cirrus Logic, Inc., Austin, Texas.

DOE. 2000. High Performance Commercial Buildings. A Technology Roadmap. A 20Year Industry Plan for Commercial Buildings. Office of Building Technology, State and Community Programs. Office of Energy Efficiency and Renewable Energy. U.S. Department of Energy, Washington, DC. Available at : http://www.eere.energy.gov/buildings/documents/pdfs/roadmap_lowres.pdf.

FCC. 2004. Part 15 - Radio Frequency Devices, Code of Federal Regulation 47 CFR Ch. I (July 12, 2004. Federal Communications Commission. Washington, D.C.

Lechelt, W.M., J.R. Skorpic, K.L. Silvers, R.W. Szempruch, D.G. Douglas, and K.O. Fein. 2002. "Remote-Reading Safety And Safeguards Surveillance System For 3013 Containers,” Waste Management 2002 Symposium, Tucson, AZ, February 24-28.

Microsoft. 2001. Visual Basic 6.0. Microsoft Corporation, Redmond, WA.

Veris. 2003. Installation Instructions H900 Split-Core Go/No Current Switch. Veris Industries. Portland, Oregon. Available at http://www.veris.com/pdf/cs/sensor/digital/H900install.pdf. 


\section{Distribution}

No. of

Copies

\section{OFFSITE}

U.S. Department of Energy

Office of the Building Technologies

FORS EE-2J

Washington, DC 20585

ATTN: D. Hansen
No. of

Copies

ONSITE

DOE Richland Operations Office

K. Williams K8-50

Pacific Northwest National Laboratory

Hanford Tech Library $\quad$ P8-55 